\title{
ANALYSIS OF WHISTLERS REGISTRATION DATA OBTAINED BY SSAN SYSTEM ON SUBAURORAL STATION IN YAKUTSK
}

\author{
Rustam Karimov ${ }^{1 *}$, Vladimir Mochalov ${ }^{2}$, Anastasia Mochalova ${ }^{2}$, Lena Tarabukina ${ }^{1}$, \\ Vyacheslav Argunov ${ }^{1}$, Mikhail Gotovcev ${ }^{1}$ \\ ${ }^{1}$ Yu.G. Shafer Institute of Cosmophysical Research and Aeronomy of SB RAS, 677980, Republic of \\ Sakha (Yakutia), Yakutsk, 31, Lenin ave., Russian Federation \\ ${ }^{2}$ Institute of Cosmophysical Research and Radio Wave Propagation of FEB RAS, 684034, Kamchatka \\ region, Elizovskiy district, Paratunka, 7, Mirnaya str., Russian Federation
}

\begin{abstract}
Since from November 2017 to August 2018, synchronous registration of atmospherics and whistlers at the radiophysical station "Oibenkyol", began in the operational mode within the network SSAN/VLF ("Sensor signal analysis network/Very low frequency"). The classification and the characteristics of the registered whistlers are carried out. The correlation analysis of the number of the whistlers registered by the SSAN/VLF with the number of lightning registered by the WWLLN is used to determine the location of lightning sources of whistlers in the opposite hemisphere in the magnetoconjugate point at South of Australia. Thus, the SSAN/VLF make possible the distance monitoring of the dynamics of the various geophysical processes changes. The large number of registered nose whistlers allow performing the statistical analysis of processes occurring in the magnetosphere' plasma.
\end{abstract}

\section{Introduction}

The main means of regular based diagnostics of the plasmosphere are observations of the whistlers on ground-based stations. Currently, there are a limited number of stations in the world where such observations are conducted. The whistler method is effective in studying plasma properties and its regular variations. The probability of receiving whistlers is maximum at medium latitudes and on average the duration of their registration is several hours per day.

Penetrating through the ionosphere into the magnetosphere, the VLF-emissions from lightning discharges can has "duct" and "not-duct" propagation paths in a magnetized magnetospheres' plasma. Important to understand how the whistlers spread to the observation point, when the ones leave the magnetosphere through the ionosphere. Also it is important to know the characteristics of thunderstorm activity in the magnetoconjugated region in relation to the observation point.

The study of the propagation of whistlers at Yakutsk had being carried out in the Laboratory of Radio Emissions of Ionosphere and of Magnetosphere of the ChICRA SB 
RAS earlier [1-2]. Based on the observations at a latitude of $62 \mathrm{~N}$, it is obtained that clockwise polarized magnetosphere VLF emissions emanate from the ionosphere into the Near-Earth's waveguide, as a rule, at zenith angles not less than 60 [1]. It was also shown that a low-frequency whistler, usually coming from high latitudes to the observation station at Yakutsk, have the upper frequency usually does not exceed $4 \mathrm{kHz}$. A dispersion analysis of the signals suggests that whistlers come from distances corresponding to the magnetosphere's regions with $\mathrm{L}>4.5$. The most probable time of observations is dawn hours. The LF whistler signals contain two components with linear and elliptical polarization. The prevailing component of a whistler signal is linearly polarized with zenith angles of arrival 90 degrees. The elliptically polarized component arrives with zenith angles typical of magnetosphere VLF emissions, such as hiss and chorus [2].

In November 2017, synchronous registration of atmospherics and whistlers in the radio physical observation stations in Yakutsk began in the operational mode within the network SSAN/VLF. Extending the investigate some aspects of the propagation and the characteristics of a whistlers, recorded using the equipment that operates in continuous mode with automatically whistlers detector, in this paper it is reviewed the most frequency recorded types of whistlers and also determined the location of their lightning sources of whistlers using the WWLLN system [3].

\section{Instruments}

The VarSITI have decided to support IKIR FEB RAS database construction entitled "Creation of a database for atmospheric and whistler events detected in the Russian Far East"[4]. The new software-hardware complex "Sensor signal analysis network" (SSAN)[5] for distributed, time synchronized monitoring of Very Low Frequency (VLF) radiation allows us to solve a number of problems associated with investigation of lightning activity, monitoring of whistler and search for their lightning sources [6-7]. At present, the SSAN endpoints make registrations in the operational mode at Paratunka (KAR), Yakutsk (OIB) and Neryungri (NER). Table 1 lists of the SSAN endpoints.

Table 1. The list of the SSAN endpoints.

\begin{tabular}{|c|c|c|c|c|}
\hline Call sign & Status & Latitude & Longitude & Location \\
\hline KAR & Operative & $\mathrm{N} 52^{\circ} 49^{\prime}$ & E $158^{\circ} 07^{\prime}$ & $\begin{array}{c}\text { Radiophysical station } \\
\text { «Karimshino», Paratunka, } \\
\text { Kamchatka region, Russian } \\
\text { Federation }\end{array}$ \\
\hline$O I B$ & Operative & $N 61^{\circ} 55$ & $E 129^{\circ} 21$ & $\begin{array}{c}\text { Radiophysical station } \\
\text { «Oibenkyol»,Yakutsk, } \\
\text { Republic of Sakha (Yakutia), } \\
\text { Russian Federation } \\
\end{array}$ \\
\hline NER & Operative & $\mathrm{N} 56^{\circ} 39$ & E $124^{\circ} 42$ & $\begin{array}{c}\text { Neryungri, Republic of } \\
\text { Sakha (Yakutia), Russian } \\
\text { Federation }\end{array}$ \\
\hline TOM & Testing & $\mathrm{N} 56^{\circ} 27^{\prime}$ & E $084^{\circ} 56^{\prime}$ & $\begin{array}{l}\text { Tomsk, Tomsk Oblast, } \\
\text { Russian Federation }\end{array}$ \\
\hline TIX & Testing & $\mathrm{N} 71^{\circ} 35^{\prime}$ & E $128^{\circ} 46^{\prime}$ & $\begin{array}{c}\text { Tiksi, Republic of Sakha } \\
\text { (Yakutia), Russian } \\
\text { Federation }\end{array}$ \\
\hline VLD & Planned & $\mathrm{N} 43^{\circ} 07^{\prime}$ & E $131^{\circ} 55^{\prime}$ & $\begin{array}{l}\text { Vladivostok, Primorsky } \\
\text { Krai, Russian Federation }\end{array}$ \\
\hline
\end{tabular}


The spatial configuration of the network is shown on the figure 1. Each the SSAN endpoint can analyze the time synchronized signals and transmit the collected information to one or several collecting centers [http://www.ikir.ru/en/Departments/Paratunka/lre/ Events/varsiti-2017.html]. The figure 2 show the block-diagram of main hardware components used for whistler registration. The signal from the electrical pin-antenna comes to a preamplifier and then to a sound card linear input (applied as one of ADC variants). The preamplifier gain is $32 \mathrm{~dB}$ for frequency range to $100 \mathrm{kHz}$ and the discretization frequency of the sound card is $192 \mathrm{kHz}$ with a 24-bit resolution. PPS signal from Glonass/GPS module also comes to a sound cards linear input that allows us to make time

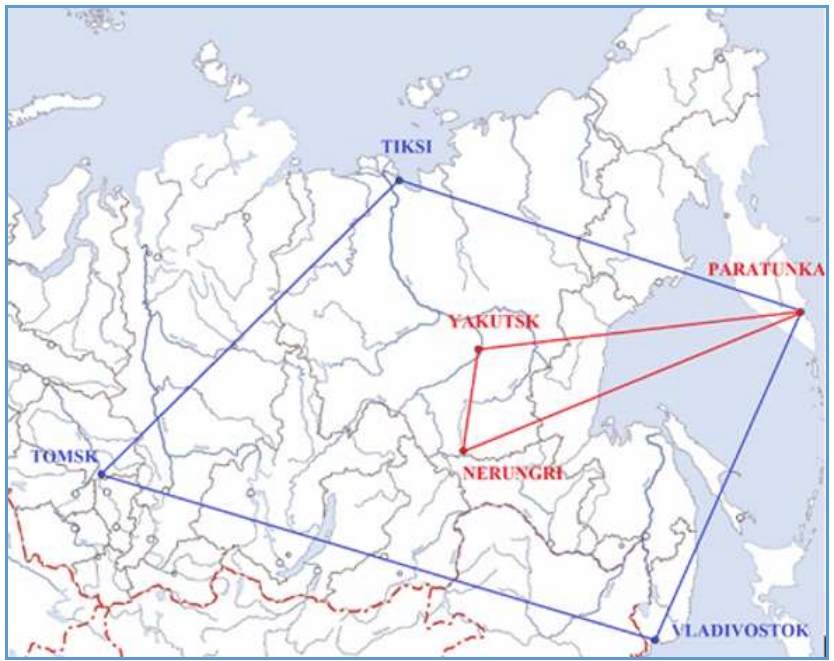

Fig. 1. The spatial configuration of the SSAN.

synchronization of the measurements at different sensor network F-nodes. The NMEAsignal comes to a mini-PC to set the system time and to determine the F-node location. After digitization, the general signal from the sound card linear input comes to the mini-PC for stream analysis processing [4].

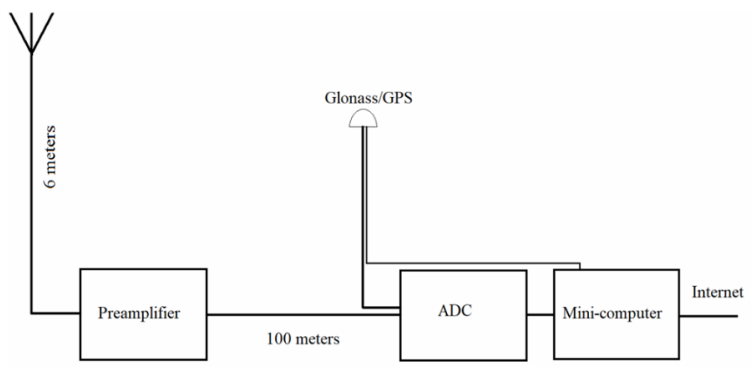

Fig. 2. The block-diagram of main hardware components used for whistler registration at "Oibenkyol" endpoint of the SSAN/VLF. 


\section{Types of registered whistlers}

During the period from November 2017 to August 2018, whistlers were regularly observed at the subauroral station "Oibenkyol" $(\mathrm{L}=3.2)$. During this period, the automatic algorithm of whistlers recognition [8] distinguished a large number of the whistlers with various shapes. The figures 3-6 show the typical and anomalous shapes of whistlers. In the monograph [9] it is described in detail the typical whistler ones that were observing at various latitudes in middle of the last century. The observations at the "Oibenkyol" showed, that although the endpoint is at medium latitudes $(\sim 62 \mathrm{~N})$, the whistlers with a nose frequency are observed regularly as well as during a weak geomagnetic activity.

Figure 3 shows typical shapes of electronic whistlers for the given latitude. The higher frequency of the whistlers more than $10 \mathrm{kHz}$. Figure 3 a shows a single one-hop whistler that propagated through the magnetosphere duct without return reflection, because the source is a lightning, that was born in a conjugate region at South Australia during wintertime in northern hemisphere. As compared with the single one-hop whistler shown in the figure $3 \mathrm{~b}$, the passage through the ionosphere to the registration point was at least multipath, but at the same time rather localized. The figure $3 \mathrm{c}$ shows a two-component whistler (odd hops), and in the figure $3 \mathrm{~d}$ a three-component whistlers.

The figure $4 \mathrm{a}-4 \mathrm{c}$ shows the multi-component whistlers with the nose frequencies. The higher frequency of the whistlers about $10 \mathrm{kHz}$. The widespread one-hop and three-hop whistlers (fig. 4a), multicomponent nose whistlers with decreasing nose frequency (fig. 4b)" echo-train" whistlers with increasing nose frequency (fig. 4c) and proton whistler (fig. $4 d)$ are presented.

In the spectrums of the signal registered at the "Oibenkyol" endpoint of SSAN/VLF are presented in the figure 5 it can see the whistlers during an activity of a chorus and a hiss (fig. 5b-5d). The figure $5 \mathrm{a}$ are shown the multipath nose whistler, witch structure is similar both for time and for frequency with next whistlers those can be repeated for about one-two hour. In the figure $5 \mathrm{~b}$ can see the multipath nose whistler, that limited to a narrow-banded hiss on low frequency at about $2 \mathrm{kHz}$. The multi-component one-hope whistlers on the figure $5 \mathrm{c}$ was registered during a chorus and a narrow-banded hiss activity. On the figure $5 \mathrm{~d}$ the multicomponent one-hope whistlers limited to a narrow-banded hiss limited on higher frequency at about $10 \mathrm{kHz}$.

The interesting effects in the spectrum of whistlers during the operation of the navigation system "Alpha" are shown in Figure 6. The whistlers "duplicate" a signals of navigation transmitters to lower frequencies than those on which the system itself operates.

It should be noted that the nose frequency generally varies from 2 to $10 \mathrm{kHz}$, and rarely exceeds $10 \mathrm{kHz}$ at the "Oibenkyol" endpoint. Figure 7-8 shows the spectrums obtained from the data of the whistler detecting at the lower latitude endpoints of the SSAN/VLF of Karimshino and Neryungri (see table 1). 

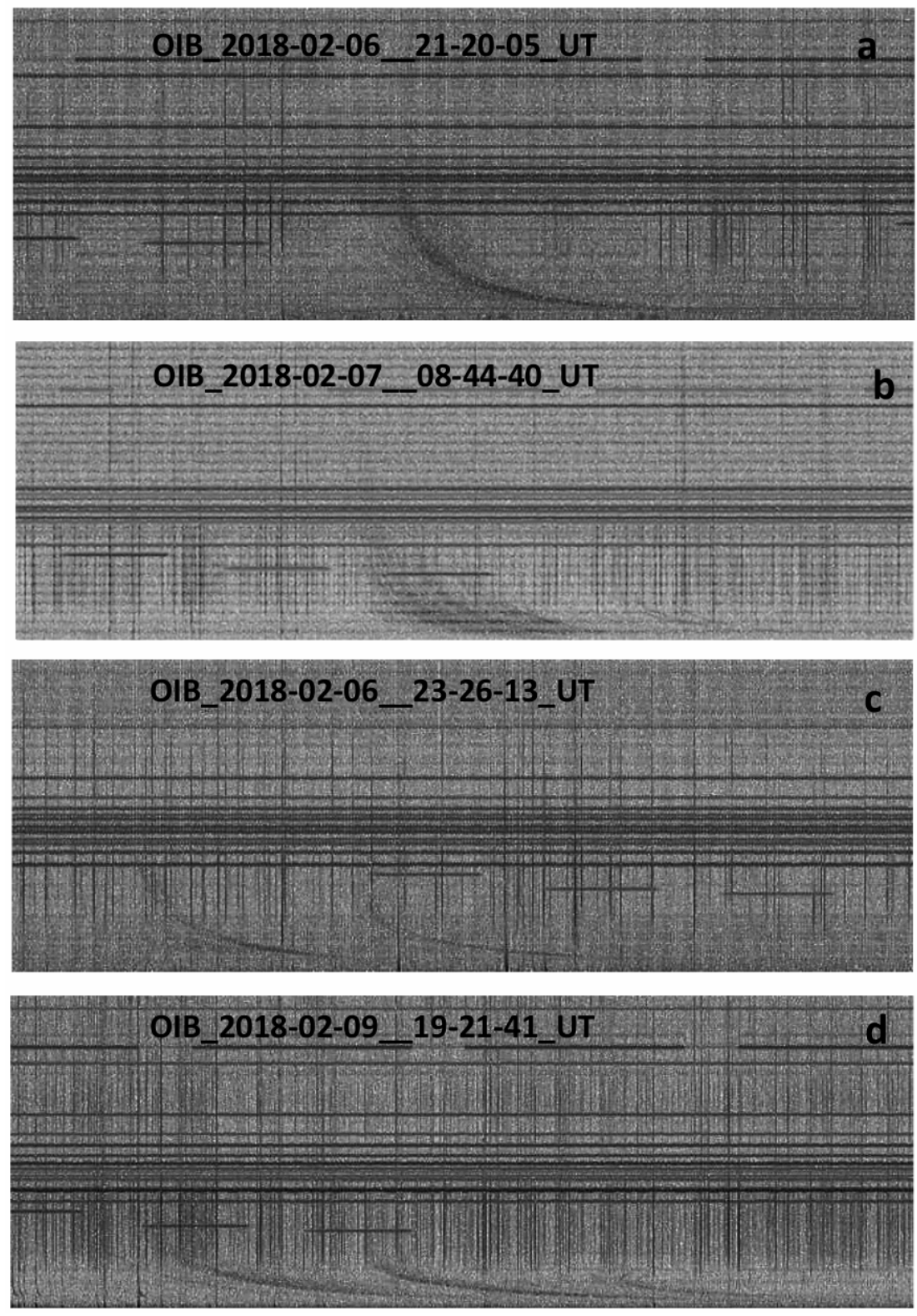

Fig. 3. The spectrums of the signal registered at the "Oibenkyol" endpoint of SSANIVLF: one-hop (a), widespread multipath one-hop (b), one-hop with three-hop (c) and one-hop, three-hop with fivehop (d) whistlers. 

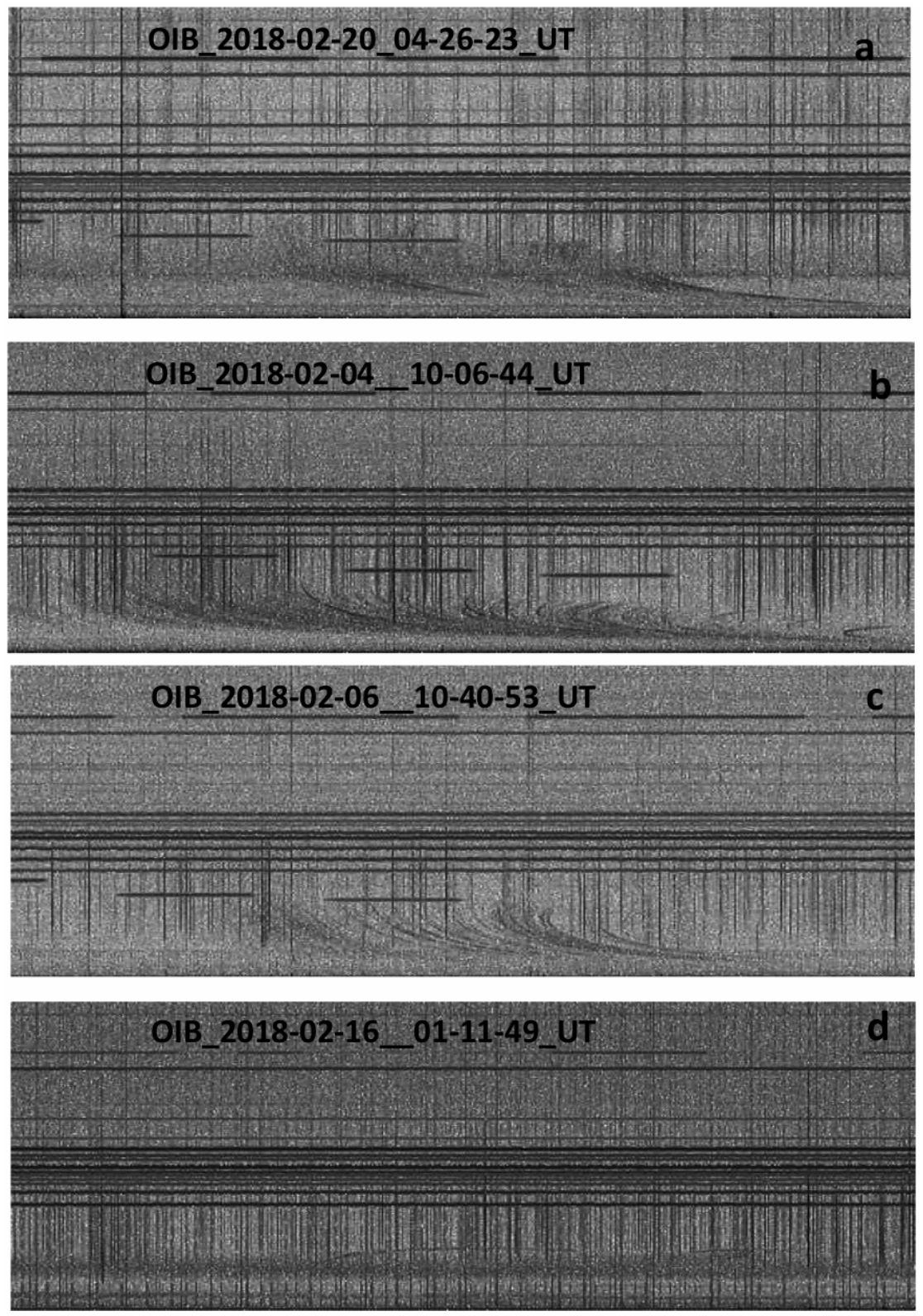

Fig. 4. The spectrums of the signal registered at the "Oibenkyol" endpoint of SSANIVLF: widespread multipath one-hop and three-hop (a), multicomponent nose whistlers with decreasing nose frequency(b), "echo-train" (c) and proton (d) whistlers. 

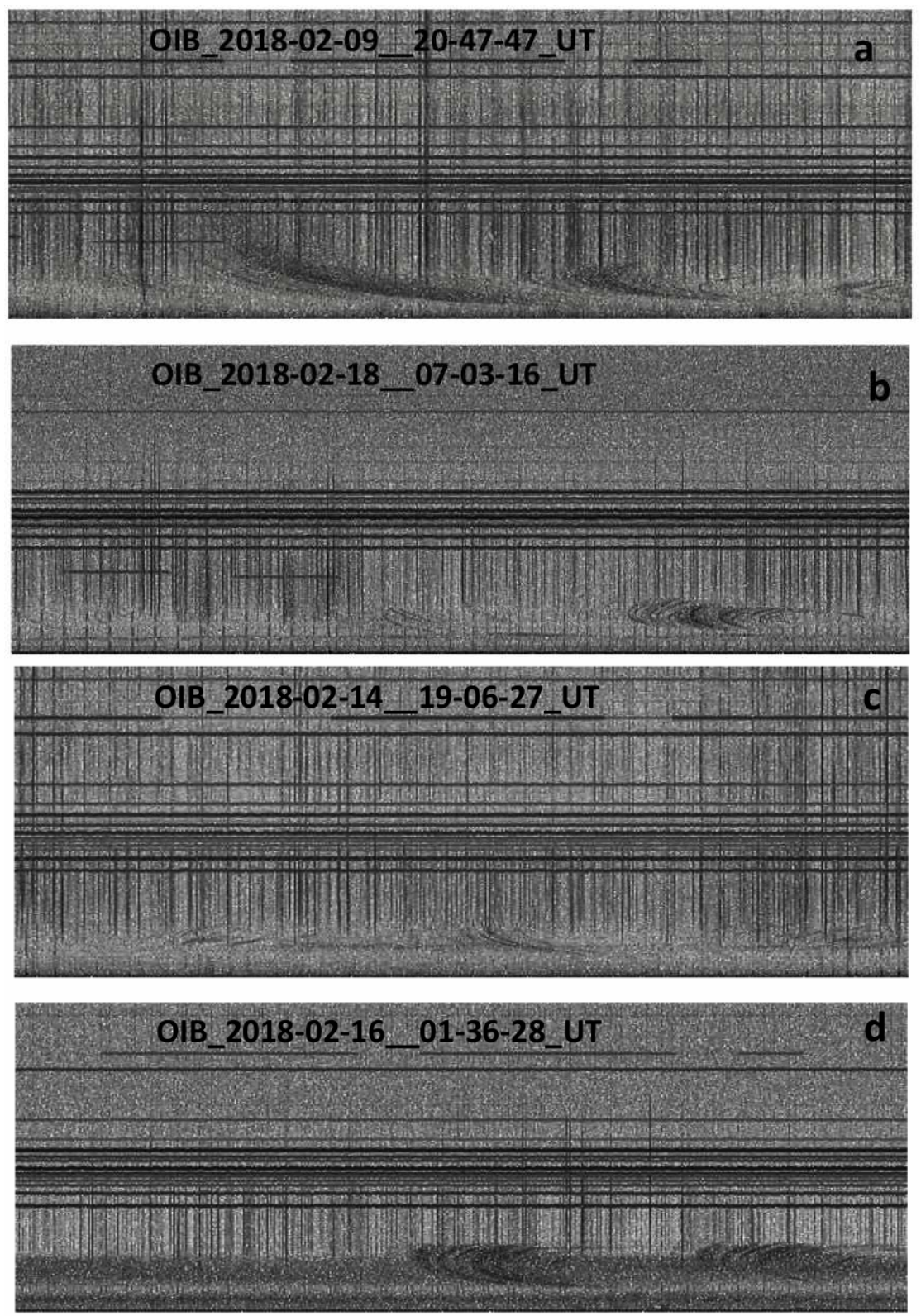

Fig. 5. The spectrums of the signal registered at the "Oibenkyol" endpoint of SSAN during chorus and hiss activity. 

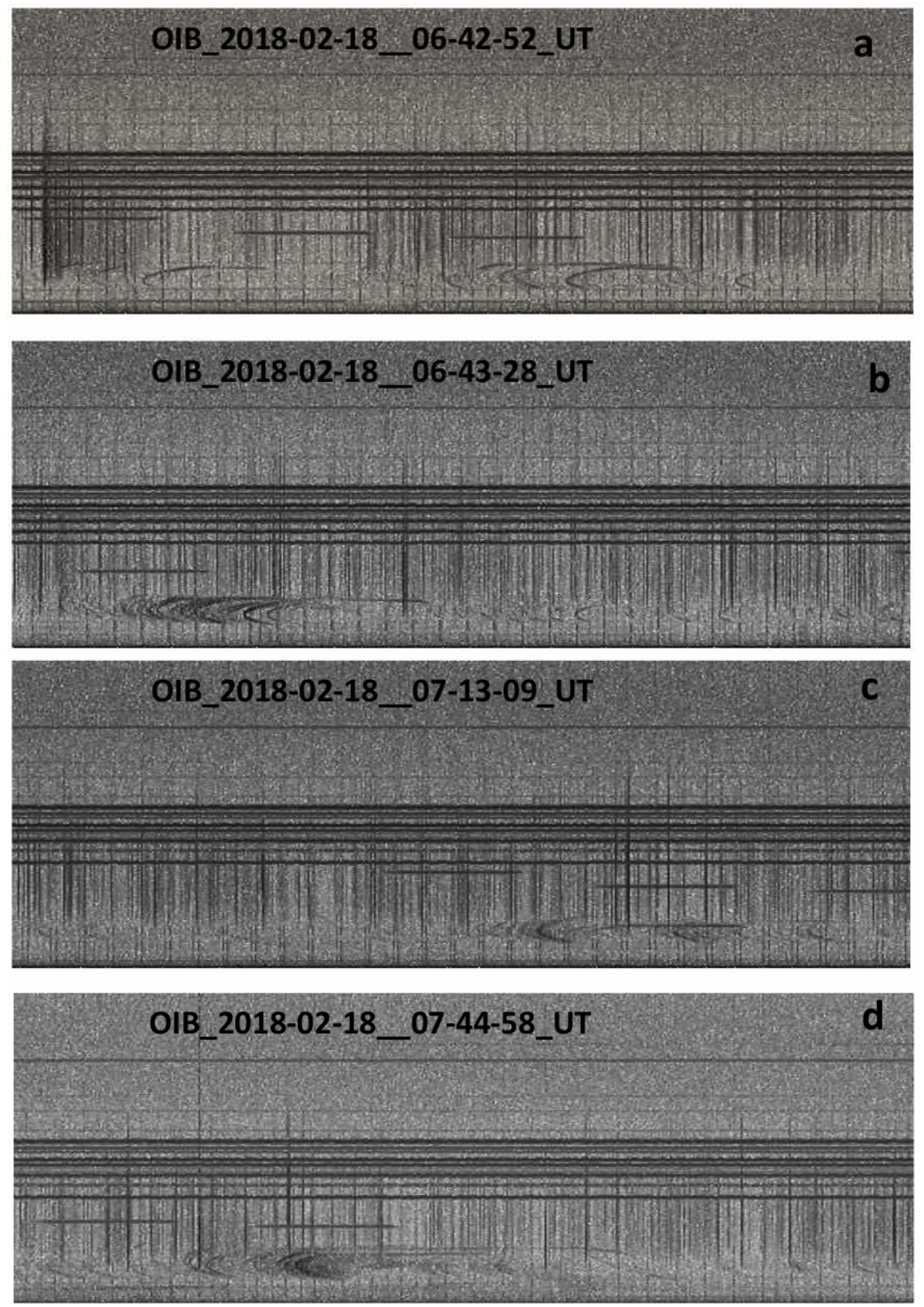

Fig. 6. The spectrums of the signal registered at the "Oibenkyol" endpoint of SSANIVLF: 

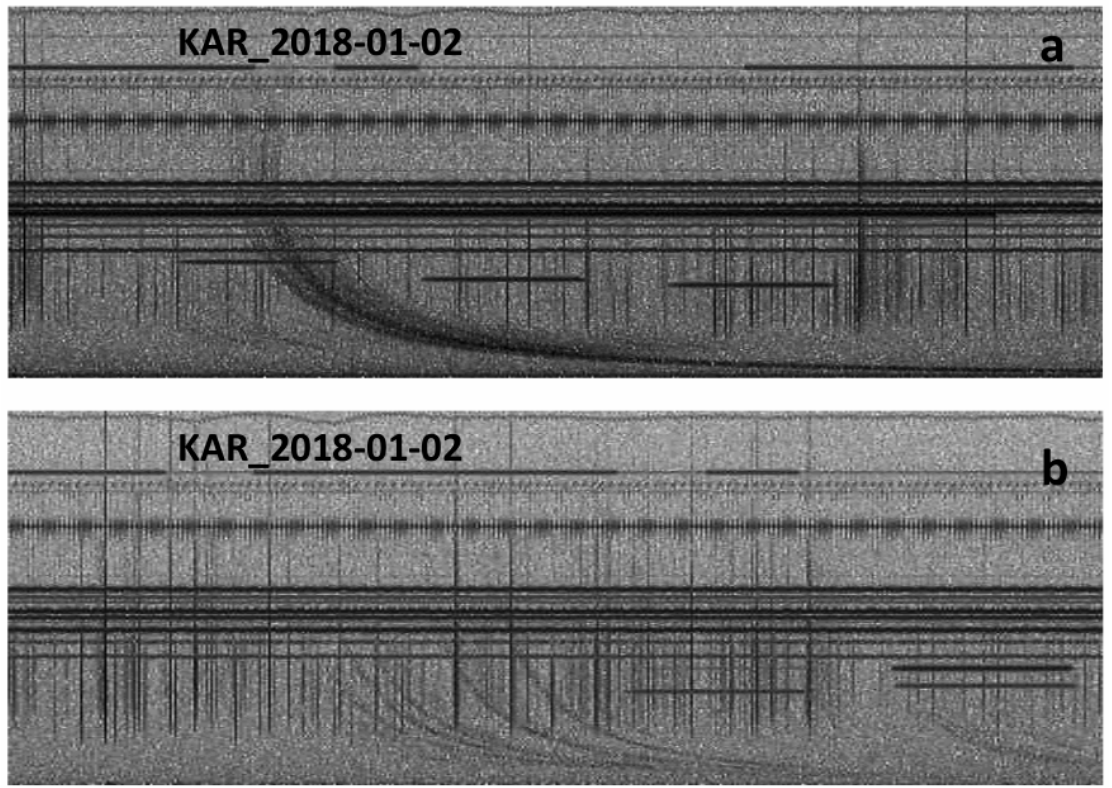

Fig. 7. The spectrums of the signal registered at the "Karimshino" endpoint of SSANIVLF.
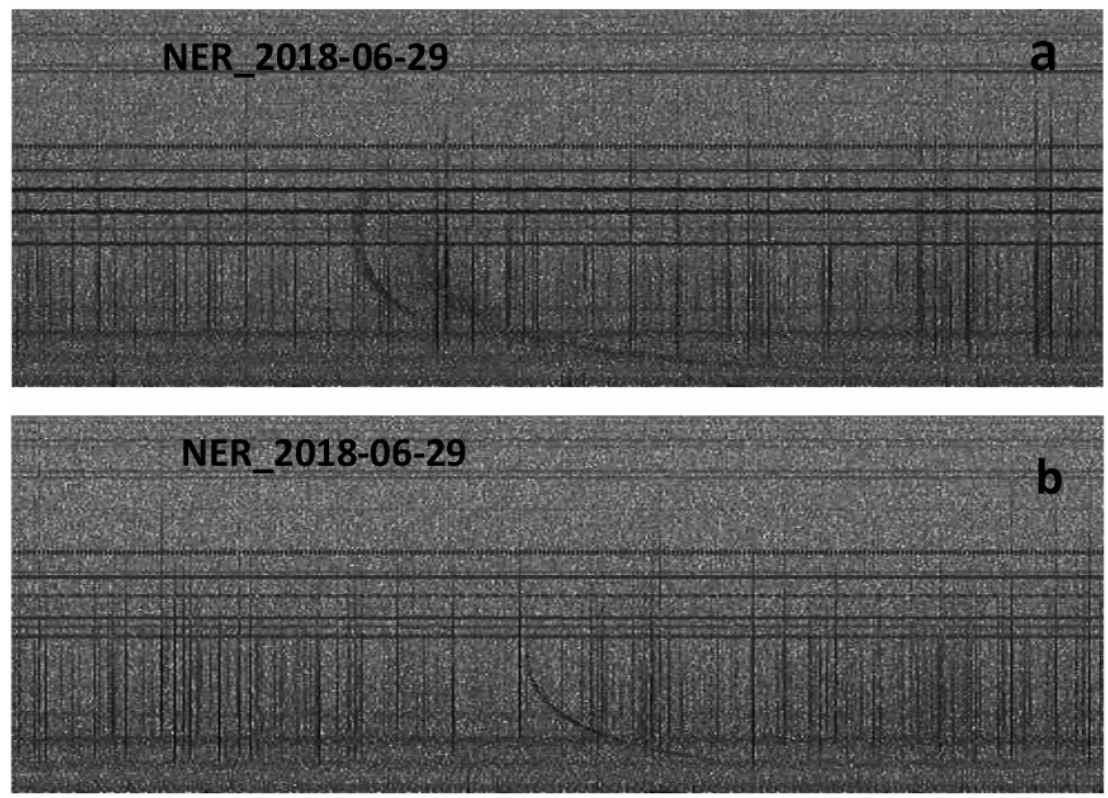

Fig. 8. The spectrums of the signal registered at the "Neryungri" endpoint of SSAN\VLF. 

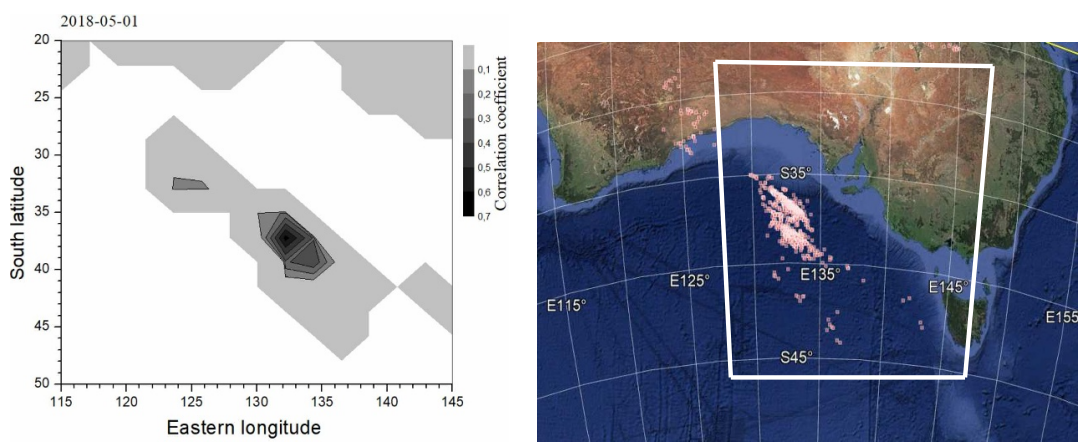

Fig. 9. The distribution of the correlation coefficients (left panel) and the lightning location (right panel) on the South Australia at 5 January 2018 year.

WWLLN minute data, 2018-01-05

Whistlers per minute, 2018-01-05
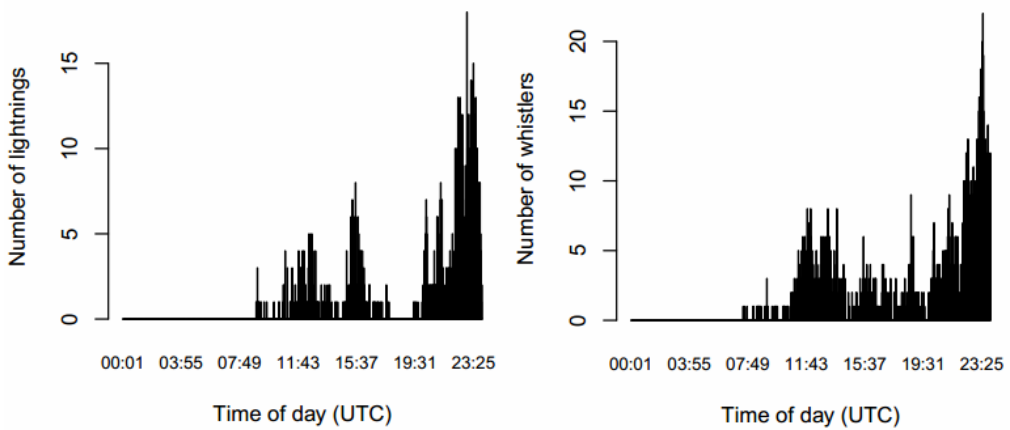

Fig. 10. The minute variation of lightning activity on the South Australia and of the whistlers registered at the "Oibenkyol" endpoint at 5 January 2018 year. $(\mathrm{R}=0.643)$

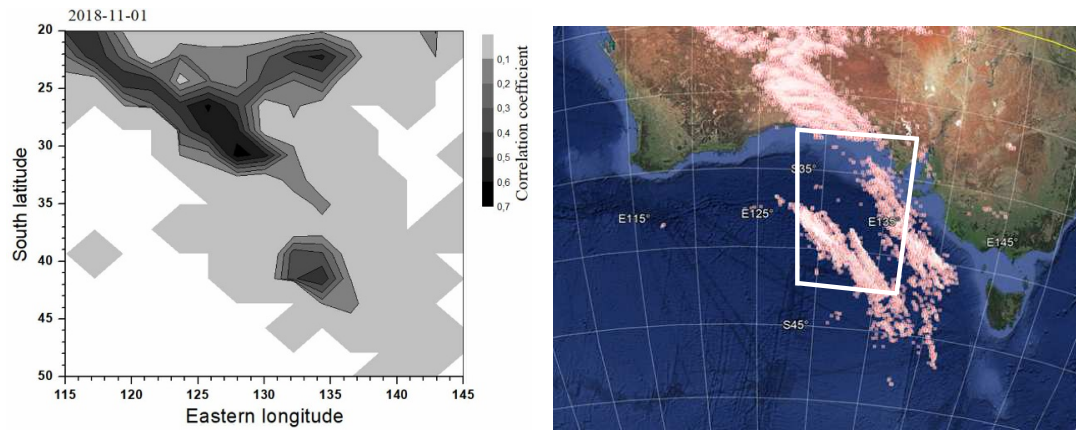

Fig. 11. The distribution of the correlation coefficients (left panel) and the lightning location (right panel) on the South Australia at 11 January 2018 year. 
WWLLN minute data, 2018-01-11

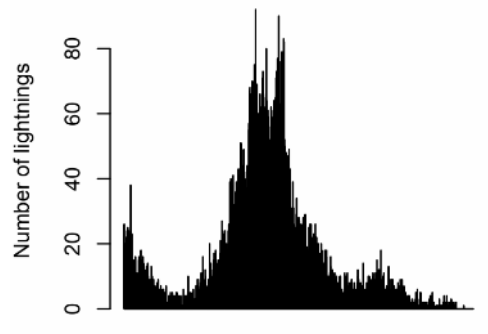

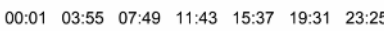

Time of day (UTC)
Whistlers per minute, 2018-01-11



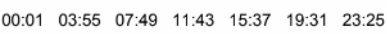

Time of day (UTC)

Fig. 12. The minute variation of lightning activity on the South Australia and of the whistlers registered at the "Oibenkyol" endpoint at 11 January 2018 year. $(\mathrm{R}=0.726)$
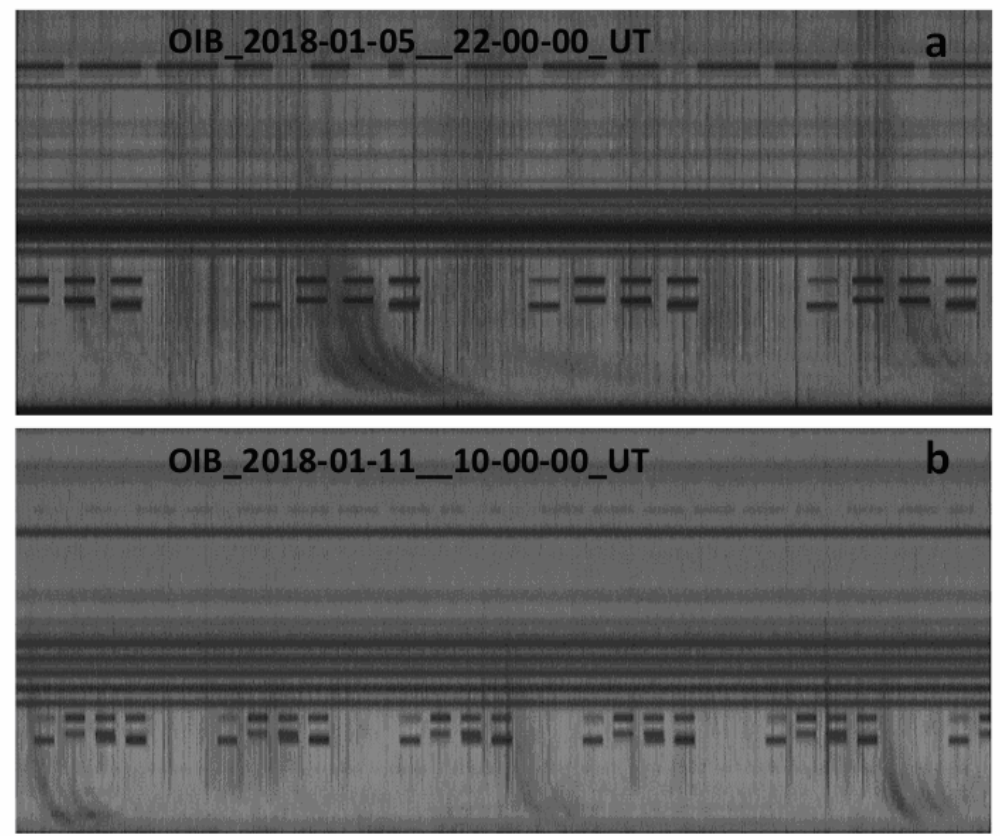

Fig. 13. The spectrums of the signals registered at the "Oibenkyol" endpoint of SSAN $\backslash$ VLF at maximum of whistlers activity at 5 (a) and 11 (b) January 2018 year. 


\section{Location of lightning source of whistlers}

In order to determine the conjugate region, where the lightning activity gave rise to whistlers, which are recorded at the "Oibenkyol", a correlation analysis was applied. It was selected the days when a high frequency of registered whistlers is observed at the observation endpoint. These days are 5 and 11 January 2018 year. The analysis used data of lightning detection by the WWLLN. The main region was chosen with the following coordinates: longitude from $100 \mathrm{E}$ to $180 \mathrm{E}$ and latitude from $20 \mathrm{~S}$ to $70 \mathrm{~S}$. This region was divided into cells with a 1-degree size both for a longitude and a latitude. For each cell, a correlation analysis was performed. Thus, the regions in which the correlation coefficient was greater than 0.1 were selected. The figures 9 and 11 on left panels show the distribution of the correlation coefficients between a minute variation of lightning activity on the South Australia and one of the whistlers registered at the "Oibenkyol" endpoint. The figures 9 and 11 show the lightning location for the same region on right panels.

To clarify the region boundaries of thunderstorm sources of whistlers, the Spearman correlation analysis was performed. It was found that on 5 January, when the threshold is selected more than 1000 whistlers, the region had coordinates (123E, 27S; 143E, 47S) (white rectangle in the figure 9 on right panel), where the correlation coefficient between the number of whistlers and lightning equal 0.643 . A comparison of the daily variations of the lightning number and of the whistlers number for the determined region at 5 January 2018 year is shown in the figure 10. On 11 January the correlation coefficient equal 0.726 for threshold more than 2000 whistlers for region (128E, 32S; 138E, 42S) (white rectangle in the figure 11 on right panel). A comparison of the daily variations of the lightning number and of the whistlers number for the determined region at 11 January 2018 year is shown in the figure 12 .

On the other days during the period from November 2017 to August 2018, when the number of whistlers per day exceeded 2000, no significant positive correlation was found.

On the figures 13a and 13b are shown dynamic spectrum of VLF-emissions with groups of widespread multipath whistlers at the maximum of the daily variation of the number of the whistlers registered at the "Oibenkyol" endpoint of SSAN/VLF on January 5 and 11 respectively.

\section{Conclusion}

The new software-hardware complex "Sensor signal analysis network" (SSAN) for distributed, time synchronized monitoring of VLF-radiation allows us to solve a number of problems, one of those is a monitoring and investigation of whistler and search for their lightning sources. During the period from November 2017 to August 2018, whistlers were regularly observed at the subauroral $(\mathrm{L}=3.2)$ "Oibenkyol" SSAN/VLF endpoint. During this period, the automatic algorithm of whistlers detecting distinguished a large number of the whistlers with various shapes, the analysis of which makes it possible to determine the conditions for the propagation of whistlers in the ionosphere and magnetosphere. The nose frequency generally varies from 2 to $10 \mathrm{kHz}$, and rarely exceeds $10 \mathrm{kHz}$ at the "Oibenkyol" endpoint. It was found that on January 2018 year in the opposite hemisphere in relation to Yakutsk region of lightning sources of whistlers has coordinates (123E, 27S; 143E, 47S), where the correlation coefficient between the number of whistlers and lightning more than 0.64 . 
The work begun will make it possible to further monitor the dynamics of changes in various geophysical processes, and a large number of registered nasal whistlers can now already perform a statistical analysis of processes occurring in the magnetospheres' plasma.

The acknowledgments. This work is partially supported by Project II.16.2.1 (registration number AAAA-A17-117021450059-3), RFBR grant 18-35-00215 and RFBR grant 18-45-140037-r_a. The creation of a database for atmospheric and whistler events detected in the Russian Far East was supported by the VarSITI.

\section{References}

1. V.A Mullayarov., V.I. Kozlov, Advances in Space Research 20(3), 517 (1997)

2. V. Mullayarov, S.I. Lvov, V.I. Kozov, Geomagnetism and Aeronomy 45(2), 189 (2005)

3. C.J. Rodger, S Werner, J.B. Brundell, E.H Lay, N.R. Thomso, R.H. Holzworth, R.L. Dowden, Annals of Geophysics 24, 3197 (2006)

4. V.A. Mochalov, G.I. Drugin, R.R. Karimov, B.M. Shevtsov, N.V. Cherneva, A.V. Mochalova, M.S. Permyakov, A.N. Droga, VarSITI Newsletter, 16, 8 (2018)

5. V Mochalov, A. Mochalova, VIII International Conference "Solar-Terrestrial Relations and Physics of Earthquake Precursors" 6 (2017)

6. V.A. Mochalov, M.S. Permyakov, N.V. Cherneva, A.V. Mochalova, Proc. SPIE, 23nd International Symposium on Atmospheric and Ocean Optics: Atmospheric Physics, 4 (2017)

7. V.A. Mochalov, R.R. Karimov, G.I. Drugin, N.V. Cherneva, A.V. Mochalova, M.S. Permyakov, A.N. Droga, V.V. Argunov, A.A. Toropov, Abstract. VERSIM (2018)

8. V Mochalov, A. Mochalova, IX International Conference "Solar-Terrestrial Relations and Physics of Earthquake Precursors" (2018)

9. R. A. Helliwell, Whistlers and Related Ionospheric Phenomena (Standfort University Press, 1965) 